\title{
Removal of Thermally Sprayed Coatings Using a Plain Water Jet*
}

\author{
Chiharu FUKUSHIMA**, Norikazu ITO***, Yoshiko SHINHARA** \\ and Mitsuo KIDO** \\ **Department of Mechanical Systems Engineering, Hiroshima Institute of Technology \\ 2-1-1 Miyake, Saeki-ku, Hiroshima 731-5193, Japan \\ E-mail: fkshima@cc.it-hiroshima.ac.jp \\ ${ }^{* * *}$ NISSEN Chemitec Corporation \\ 2500-1, Ohgohara, Komono, Mie 510-1222, Japan
}

\begin{abstract}
A plain water jet is applied for the removal of plasma sprayed $\mathrm{Al}_{2} \mathrm{O}_{3}$ and $\mathrm{ZrO}_{2}$ coatings on stainless steel (JIS SUS304) substrates. The water jet impinges perpendicularly to the surface of the specimen with a constant traverse rate of $V_{T}=$ 150 or $300 \mathrm{~mm} / \mathrm{min}$. The jet pressure $\left(J_{p}=70-300 \mathrm{MPa}\right)$ and the standoff distance $\left(D_{s}=5-30 \mathrm{~mm}\right)$ are systematically varied. The flow and erosive properties of the water jet are experimentally investigated to avoid unwanted erosion of the substrate. Particle image velocimetry (PIV) analysis is also applied, but only for lower jet pressure (less than $10 \mathrm{MPa}$ ) conditions. The results show that coating removal is significantly dependent on the material properties, especially the adhesion strength and porosity. Coating removal is successfully achieved within the present experimental conditions. The reported data suggest that the water jet process is a useful method for coating removal, although further verification and understanding of the fracture mechanisms are required.
\end{abstract}

Key words: Plain Water Jet, Erosive Properties, Thermally Sprayed Coatings, Coating Removal

\section{Introduction}

A variety of thermally sprayed ceramic coatings, which have significant heat, wear, and corrosion resistance, have been used for many practical purposes. However, the ceramic coatings can become locally delaminated and cracked due to thermal or mechanical loads.

The objective of the present study is to develop a technique for the removal of damaged coatings and reuse of the substrate. To achieve this, it is necessary to remove only the damaged area without causing any extra damage to the remaining parts and the substrate.

As previously reported ${ }^{(1)}$, the principle of the water jet process can be classified as follows: (a) erosion due to dynamic pressure (plain or abrasive ${ }^{(2)}$ water jet), (b) erosion due to the impact load of water droplets, (c) hydraulic penetration in a preexisting crack or erosion pit, (d) unsteadiness (e.g., pulsating water jet), (e) thermal stress due to the difference in temperature between the water jet and the target materials (e.g., dry ice blasting $\left.^{(3,4)}\right)$. These effects are mutually related and the erosion or removal of coating materials will occur.

In the case of a plain water jet ${ }^{(7-12)}$, principles (a), (b) and (c) are significantly dependent on the standoff distance, because the turbulent jet develops in a streamwise direction, and exhibits the typical features of fluid flow. Wu \& $\mathrm{Kim}^{(11)}$ summarized their use of a plain water jet, noting that a variety of parameters should be considered. Ding et al. ${ }^{(7)}$, Shimizu 
et al. $^{(8)}$ and Shimizu ${ }^{(9)}$ conducted extensive experiments using a plain fan jet with consideration of the flow structures. A mechanism for material removal and the interaction between targets and a plain water jet ejected from a circular nozzle were considered by Kong et al. ${ }^{(14)}$ and Mabrouki et al. ${ }^{(15)}$. The water jet removal method is not a new technique; however, very little data have been published. Currently, both the mechanisms and efficiency of the water jet removal procedure ${ }^{(2-5)}$, and the environmental stress (e.g., a collection system of the debris including water ${ }^{(5)}$ ) are being investigated. The water jet process, especially that using a plain water jet, is expected to remove thermal spray coatings more effectively with less environmental stress than conventional chemical stripping $^{(6)}$ or shot blast methods.

In the present study, experiments for the removal of two types of plasma sprayed ceramic coatings, $\mathrm{Al}_{2} \mathrm{O}_{3}$ and $\mathrm{ZrO}_{2}$, were conducted to investigate the efficiency of the water jet process. The optimum conditions and mechanism of the water jet process are examined and discussed.

\section{Experimental Setup and Procedure}

\subsection{Experimental Setup and Conditions}

Experiments were conducted using a Flow International Corporation Bengal-J water jet system. The maximum operating pressure of the system is $378 \mathrm{MPa}$, and the maximum fluid flow rate is $4.69 \mathrm{~L} / \mathrm{min}$. The traverse velocity of the nozzle can be set in the range of 0 to $7260 \mathrm{~mm} / \mathrm{min}$.

A fan jet (elliptical shape) nozzle with nominal outlet diameters of $0.45 \mathrm{~mm}$ and 0.28 $\mathrm{mm}$ (an area of approximately $0.09 \mathrm{~mm}^{2}$ ) was used throughout the experiment. The jet pressure $J_{p}$, was systematically changed from 70 to $300 \mathrm{MPa}$ (using approximately 2-4.2 $\mathrm{L} / \mathrm{min}$ of the water), and the standoff distance $D_{s}$, was varied from 5 to $50 \mathrm{~mm}$. The water jet impinged perpendicularly to the surface of the target specimen. The traverse velocity of the nozzle $V_{T}$ (moves in the $x$ direction) was set at either 150 or $300 \mathrm{~mm} / \mathrm{min}$. Figure 1 shows a schematic diagram of the flow field with nomenclature and coordinate system, and a photograph of an instance of water jet exposure.

To optimize coating removal using a water jet, the features of the water jet, processing conditions, and properties of the target materials should be considered for appropriate selection. In the present study, a plain water jet issued from a fan jet nozzle was employed, due to minimal environmental stress. The optimum conditions for the water jet process were explored by systematically changing the jet pressure and standoff distance.

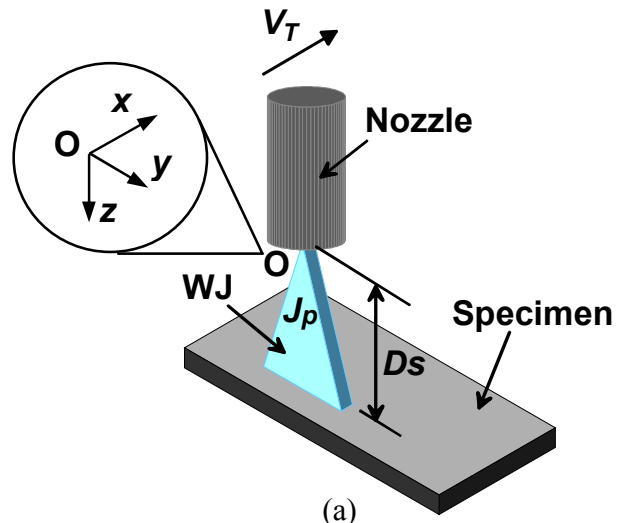

(a)

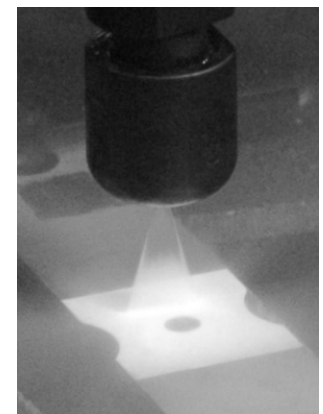

(b)

Fig. 1 (a) Schematic diagram of flow field with nomenclature and coordinate system, and (b) photograph of an instance of water jet exposure. 


\subsection{Tested Specimens and Evaluation}

Specimens of plasma sprayed coating plates were used to obtain the coating removal characteristics for the water jet process. The substrate specimen (JIS SUS304 stainless steel) was blasted with alumina particles (WA\#36 or \#60) and pre-heated, followed by thermal spraying of bond and top coats using an atmospheric plasma spraying apparatus (Technoserve Co. Ltd.). A detailed description of the equipment and spraying conditions were reported by Shinhara et al. ${ }^{(13)}$ and Ding et al. ${ }^{(7)}$.

The specimen properties are presented in Table 1. The adhesion strength is based on the JIS H8402 ceramic coatings tensile test. The porosity of the topcoat was obtained via scanning electron microscopy (SEM; Jeol JSM-5900LV) image analysis from the ratio of the open pores area to the observed area. The elastic modulus was evaluated using a nanoindentation method. Hardness was measured with a hardness testing machine (Mitutoyo HM-101).

To evaluate the water jet process, damaged or removed coating widths and the depth of the surface were observed using optical microscopy (Keyence VF-7500) and SEM, and measured with a three-dimensional roughness measurement system (Taylor-Hobson FTS S6). Qualitative X-ray diffraction (XRD; MAC Science M21X) analysis was also conducted.

\section{Results and Discussion}

\subsection{Erosive Properties of Water Jet Process}

A traversing water jet was applied for the erosion of mild steel (JIS SS400) and stainless steel (JIS SUS304) substrates to ensure unwanted erosion of the substrates. The water jet issued from a fan jet nozzle is shown in Fig. 1(b). The three-dimensional surface states were measured, and the resulting erosive conditions are mapped in Fig. 2 for the

Table 1. Properties of thermally sprayed $\mathrm{Al}_{2} \mathrm{O}_{3}[\# 1]$ and $\mathrm{ZrO}_{2}[\# 2]$ coatings.

\begin{tabular}{|c|c|c|c|c|c|}
\hline & $\begin{array}{c}\text { Thickness } \\
{[\mu \mathrm{m}]}\end{array}$ & $\begin{array}{c}\text { Adhesion } \\
\text { Strength } \\
{[\mathrm{MPa}]}\end{array}$ & $\begin{array}{c}\text { Porosity } \\
{[\%]}\end{array}$ & $\begin{array}{c}\text { Young's } \\
\text { Modulus } \\
{[\mathrm{Gpa}]}\end{array}$ & $\mathrm{Hv}$ \\
\hline$\# 1$ & $200 \pm 20$ & 10.0 & 7.4 & $64.9 \pm 0.3$ & $951 \pm 66$ \\
\hline$\# 2$ & $240 \pm 30$ & $\begin{array}{c}14.2[\mathrm{I}] \\
21.0[\mathrm{II}]\end{array}$ & 5.2 & $59.8 \pm 11.3$ & $771 \pm 20$ \\
\hline
\end{tabular}

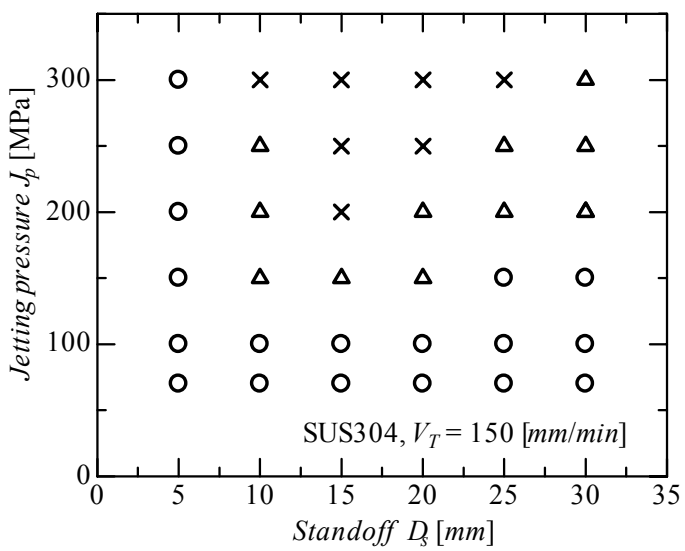

Fig. 2 Experimentally determined eroded regimes for stainless steel plates; $\mathrm{O}$ : without erosion; $\triangle$ : partly eroded; $\times$ : completely eroded. 
stainless steel specimen as a representative case. The eroded regions indicate that erosion is not caused under conditions of $J_{p} \leq 100 \mathrm{MPa}$, nor $D_{s} \leq 5 \mathrm{~mm}$. For the eroded regions, most of the specimens exhibit depths that are deeper at both_edges of the eroded groove.

The water jet extends to an approximate angle of $28-30^{\circ}$ under the present conditions. The fluid flow exhibits transparent liquid film regions (i.e. potential core region) that arise in the vicinity of the nozzle outlet, and opaque streaked regions (i.e. turbulent streaks) in the downstream region (see Fig. 1(b), Figs. A-1 and A-2). The flow regions are closely related to the mechanism of the water jet process. The liquid film region is primarily related to the dynamic pressure and hydraulic penetration of the water jet, while the streak region is related to impact load of the water droplets. The length of the liquid film region directly changes as a function of the jet pressure ${ }^{(1,9)}$. Therefore, it is necessary to select the standoff distance $D_{s}$ appropriately. This is confirmed from the results of the erosive efficiency of the water jet on mild steel plate shown in Fig. 3. The volume removed is estimated from integration of the profile for an eroded groove. The results are shown for $V_{T}=150$ and $300 \mathrm{~mm} / \mathrm{min}$ at each jet pressure $J p=150-300 \mathrm{MPa}$. It can be clearly found out that the erosive efficiency of the water jet is most significant in the region of $D_{s}=15-20$ $\mathrm{mm}$, which corresponds to the opaque turbulent streaked region.

The surface state of the mild steel specimen after water jet treatment under conditions of $D_{s}=15 \mathrm{~mm}, V_{T}=150 \mathrm{~mm} / \mathrm{min}$, and $J p=300 \mathrm{MPa}$ is presented in Figs. 4(a) and (b). The origins of the $x$-axis are different in Figs. 4(a) and (b). The surface photograph shown in Fig. 4(a) has a striped pattern and the typical surface profile of this region (Fig. 4(b))

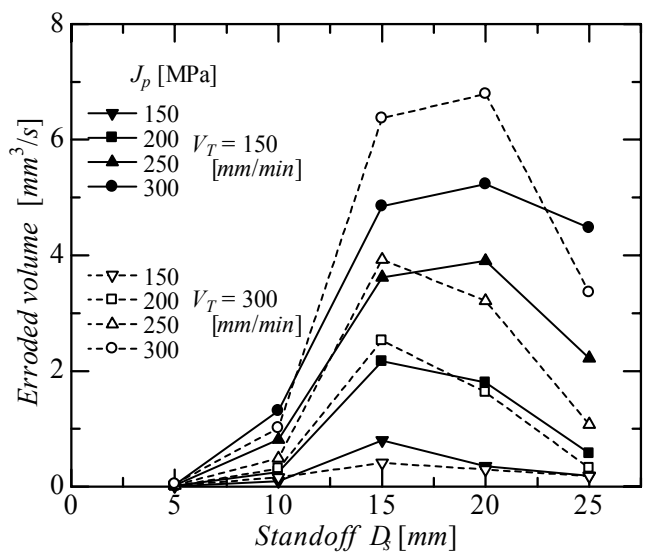

Fig. 3. Erosive efficiency of a water jet on mild steel (JIS SS400).

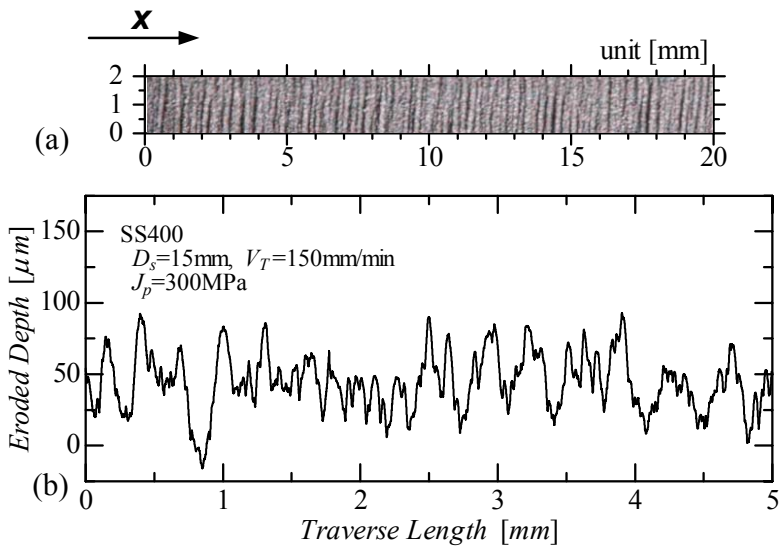

Fig. 4. (a) Surface photograph and (b) surface profile for mild steel (JIS SS400) measured in the traverse direction. 
exhibits quasi-periodic wavy patterns with a wavelength of $\lambda \approx 0.45 \mathrm{~mm}$. The wavelength corresponds to the periodic pressure of the water jet of approximately $5.5 \mathrm{~Hz}$. However, distinct peak values were not elucidated from spectral analysis of the fluctuating pressure signals. A steady state of the turbulent jet fundamentally involves intermittency, and exhibit organized ${ }^{(17)}$ (i.e. quasi-periodic) components. Therefore, further consideration of the turbulent structure as well as the operating conditions of water jet process, is required to elucidate the erosive properties of the water jet.

\subsection{Removal of Plasma Sprayed Ceramic Coatings}

The water jet process has sufficient ability to erode specimens. If the erosive efficiency is prioritized, higher jet pressures $\left(J_{p} \geq 200 \mathrm{MPa}\right)$ and the streak region of the water jet $\left(D_{s}=15-20 \mathrm{~mm}\right)$ should be applied to the water jet process, as shown in Fig. 2 . However, in order to remove only the damaged coatings and reuse the substrate, further examinations for the conditions of appropriate traverse velocity should be required. Therefore, as a first step, only a liquid film region with $D_{s} \leq 5 \mathrm{~mm}$ was applied during coating removal to prevent damage to the stainless steel substrate.
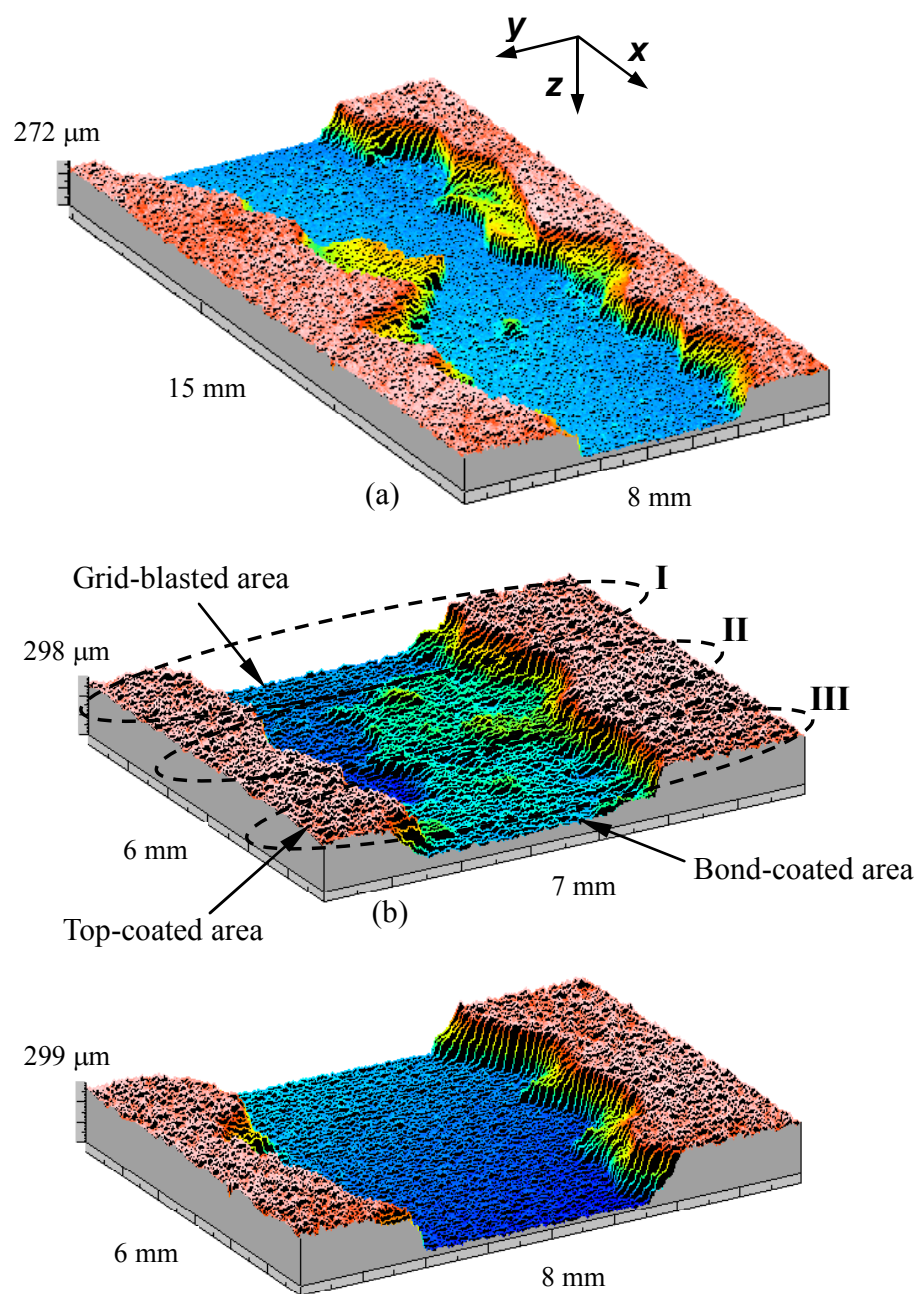

(c)

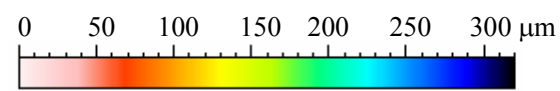

Fig. 5. 3-D surface roughness measurements for $\mathrm{ZrO}_{2}$ coated plates.

(a) \#2[I], $D_{S}=5 \mathrm{~mm}, J_{p}=100 \mathrm{MPa}$, (b) \#2[II], $D_{S}=5 \mathrm{~mm}, J_{p}=150 \mathrm{MPa}$, and

(c) \#2[II], $D_{S}=5 \mathrm{~mm}, J_{p}=200 \mathrm{MPa}$. 
Properties of tested specimens are shown in Table 1. The top coat of specimen \#1 is $\mathrm{Al}_{2} \mathrm{O}_{3}$, and that \#2 is $\mathrm{ZrO}_{2}$. The thickness is total thickness of bond and top coats. Figures 5(a)-(c) show the three-dimensional surface states obtained by roughness measurements for $\mathrm{ZrO}_{2}$ coated plate. Water jets with a standoff distance of $D_{s}=5 \mathrm{~mm}$ were impinged at jet pressures of $J_{p}=100-200 \mathrm{MPa}$. In the case of the $\mathrm{Al}_{2} \mathrm{O}_{3}$ coated plate $^{(1)}$, both the top and bond coats were completely and uniformly removed under process conditions of $D_{s}=5 \mathrm{~mm}$ and $J_{p}=100 \mathrm{MPa}$. For $\mathrm{ZrO}_{2}$ (\#2[I]) shown in Fig. 5(a), both the top and bond coatings were completely and uniformly removed. However, the results are considerably different for $\mathrm{ZrO}_{2}$ (\#2[II]), as shown in Figs. 5(b) and (c). The most significant difference between the \#1, \#2[I], and \#2[II] tested specimens is the adhesion strength, as shown in Table 1. The \#2[II] specimens were exposed to the water jet at $J_{p}=$ 150 and $200 \mathrm{MPa}$. In the case of $J_{p}=150 \mathrm{MPa}$, the removed area was discriminated into three zones I, II and III as shown in Fig. 5(b). The removed area was not uniform and the coating still remained in zones II and III. At a higher jet pressure of $J_{p}=200 \mathrm{MPa}$, the removal depth reached to $230 \mu \mathrm{m}$ within the entire groove, and became uniform, as shown in Fig. 5(c).

The precise surface state for $\mathrm{ZrO}_{2}$ specimens \#2[II] (see Fig. 5(b)) are shown in Figs. 6(a)-(c). Each profile is a representative result within the three zones I, II and III in Fig. 5(b). The depth of the groove reaches $220 \mu \mathrm{m}$ in zone I and the profile is almost flat (Fig. 6(a)), which indicates almost complete removal of the coating. However, in zone II of the specimen, a discontinuity profile is observed within the groove (Fig. 6(b)). In the deeper region of the profile, the coating is almost removed, but in the shallower region, the bond coat still remains. In zone III of the specimen, the profile in the groove is flat (Fig. 6(c)),
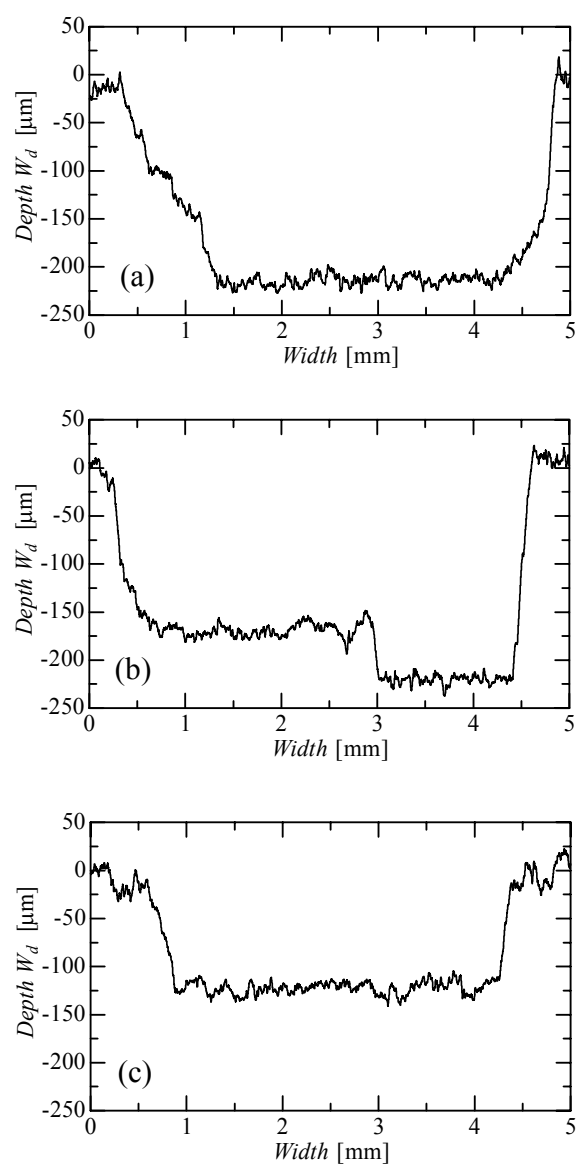

Fig. 6. Representative surface profiles for $\mathrm{ZrO}_{2}$ coated plate within three zones; (a) zone I, (b) zone II, and (c) zone III, as defined in Fig. 5(b). 
but most of the bond coat remains.

The removed surface state was also examined by XRD analysis to determine the efficiency of coating removal ${ }^{(1)}$. It is also important to determine the difference between the surface roughness of the blasted surface and the removed surface after the water jet process for consideration of the re-coating procedures. The surface after removal of the coating by the water jet process had been confirmed to be sufficiently rough to accept deposition of new coatings without the need for shot blasting ${ }^{(1)}$.

For the brittle materials, the local fracture mechanism on the failure of a multiphase brittle material (i.e. concrete) under plain water jet impingement were investigated by Momber and Kovacevic ${ }^{(16)}$. They found that the workpiece destruction by water jets is introduced at the interfaces between the matrix and inclusions producing single cracks; then several single cracks merge under the influence of water jet impingement. Other brittle materials such as thermally sprayed ceramic coatings, is porous medium characterized by porosity. Plastic deformations are less likely to occur in the ceramic coatings. In order to explain the circumstance for coating removal, it is important to determine the initial situation with consideration of the differences in porosity and the adhesion strength.

Figures 7(a)-(d) show SEM images of microstructures for $\mathrm{Al}_{2} \mathrm{O}_{3}$ and $\mathrm{ZrO}_{2}$ coatings subjected to water jets at $J_{p}=70 \mathrm{MPa}, D_{s}=15 \mathrm{~mm}$ (Figs. 7(a) and (b)), and of $J_{p}=120$ $\mathrm{MPa}, D_{s}=5 \mathrm{~mm}$ (Figs.7(c) and (d)), respectively, where coating removal was not achieved. Initiated defect such as a crack or a pit, surrounded by dotted line in Figs. 7(b) and (d), is evident in each micrograph. The defects of the coating are caused around the boundary of the splatted lamellae, despite the differences of the coating properties. The water jet impact above the fracture threshold will responsible for initiating a crack. It is difficult to describe that the fractures progress across or along the lamellae ${ }^{(14)}$; however, such phenomena occur during the initial steps of coating removal by the water jet process. The liquid film region is effective for hydraulic penetration ${ }^{(8)}$ into initiated cracks and preexisting porous locations or pits. Therefore, once such fractures occur and two or more cracks cross each other, a piece of coating is flaked off, i.e., the coating is removed.

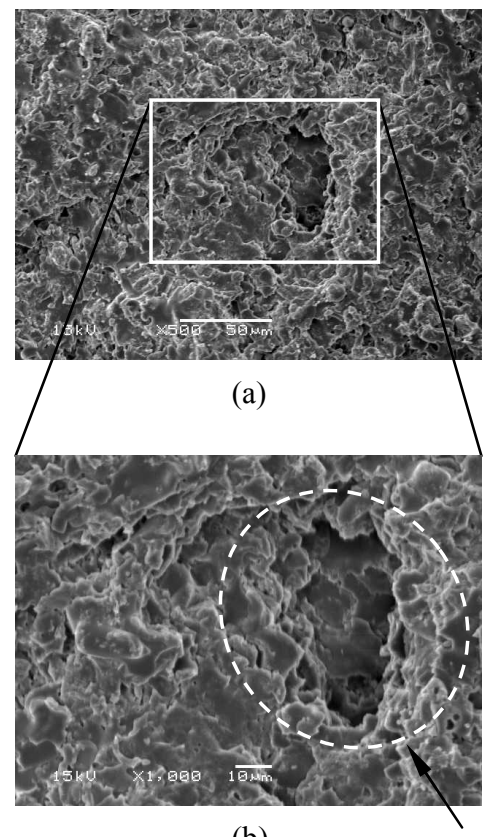

(b)
Initiated defects after water jet impingement

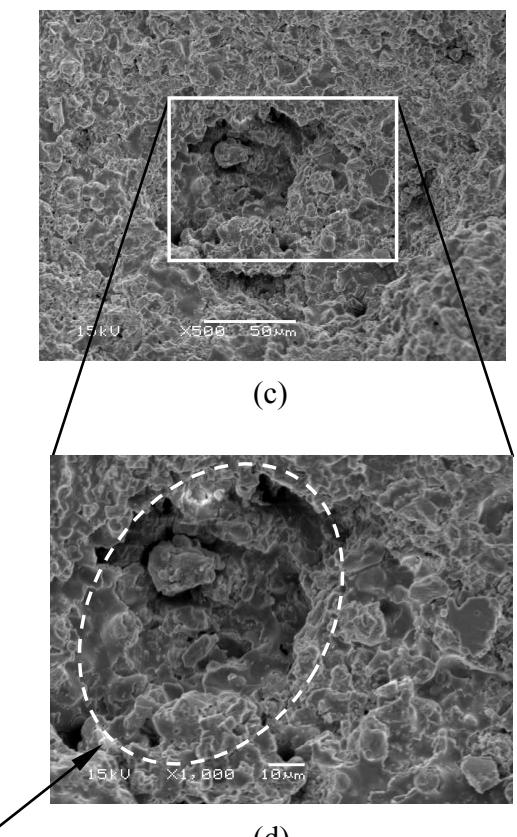

(d)

Fig. 7. SEM images of coating surface morphologies after water jet exposure; (a) and (b) $\mathrm{Al}_{2} \mathrm{O}_{3}, J_{p}=70 \mathrm{MPa}, D_{s}=15 \mathrm{~mm}$; (c) and (d) $\mathrm{ZrO}_{2}, J_{p}=120 \mathrm{MPa}, D_{s}=5 \mathrm{~mm}$. 


\section{Conclusions}

The flow characteristics and erosive properties of a plain water jet were examined and applied to the removal of thermally sprayed ceramic coatings. It was determined that there are optimum operating parameters for coating removal that are dependent on the characteristics of the water jet. The ceramic coatings was successively removed under the conditions of $D_{s} \leq 5 \mathrm{~mm}$ (i.e. the liquid film region of the jet), without causing any extra damage to the substrate. The water jet process was confirmed to be a useful method for the removal of coatings. However, the use of the streak region of a water jet should be considered for more effective coating removal. In addition, quantitative measurements of the velocity field and water jet properties are required to determine the fracture mechanisms involved.

\section{Acknowledgement}

The present work was partly supported by the Electric Technology Research Foundation of Chugoku.

\section{Appendix}

\section{A.1. Particle Image Velocimetry}

Jet pressures of $J_{p}=100-300 \mathrm{MPa}$ are applied practically; however, these pressures are too high for quantitative velocity measurements. Therefore, a much lower pressure of $J_{p}=$ $5 \mathrm{MPa}$ (exit velocity reaches ca. $100 \mathrm{~m} / \mathrm{s}$ ) was adopted for particle image velocimetry (PIV) analysis of the velocity field for convenience. The flow structure changes according to the Reynolds number; however, the results under lower pressure conditions will contribute to a qualitative understanding of the flow structure.

A colored double-exposure technique ${ }^{(18)}$ was employed to obtain PIV images. An example of a visualization image is shown in Fig. A-1(a). The visualized pattern is due to self-forming water droplets (a type of relatively large size water droplets), because it is difficult to incorporate tracer particles into the water jet. Although precise resolution is not expected, this analysis should be useful to understand the relationship between the turbulent flow properties and the fracture mechanism of coatings.

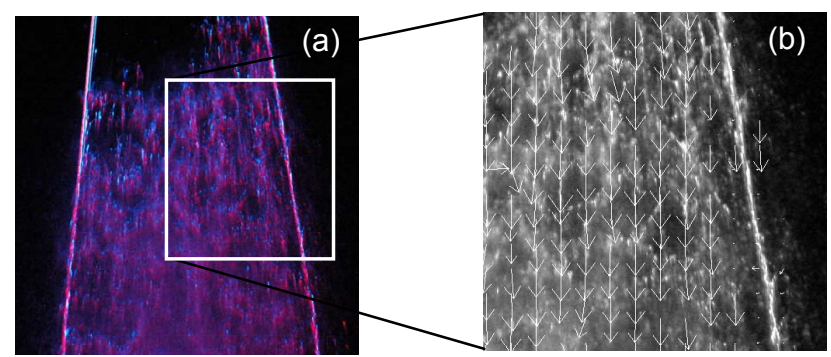

Fig. A-1. (a) Double-exposed image, and (b) mean velocity vectors for the square region indicated in (a).
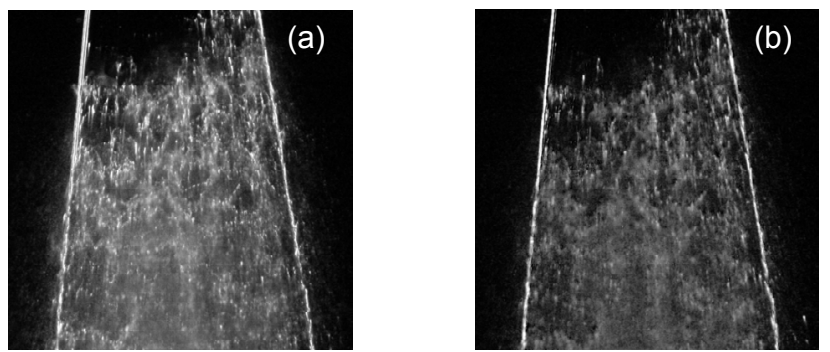

Fig. A-2. Decomposed image; (a) blue and (b) red components. 
The water jet is illuminated by a red and blue colored strobe scope. The time delay is $3 \mu \mathrm{s}$, where the patterns move about 15 pixels, which corresponds to an interrogation window size that is a quarter of $64 \times 64$ pixels. The image is then decomposed into red and blue images (shown in Figs. A-2(a) and (b), respectively), and cross-correlation of the images is achieved. The mean value is obtained from 500 photographs. The results of the mean velocity vectors for the square region indicated in Fig. A-1(a) are shown in Fig. A-1(b).

\section{A.2. Flow Properties of Plain Water Jet}

The decay of the axial mean velocity as a function of the distance from the nozzle outlet is shown in Fig. A-3(a). Figures A-3(b) and (c) show the mean velocity and turbulent intensity profiles obtained using PIV for $J_{p}=5 \mathrm{MPa}$. The axial (centerline) mean velocity increases in the streamwise direction with a maximum of $U_{m}=93 \mathrm{~m} / \mathrm{s}$ at $x=31$ $\mathrm{mm}$, which indicates that the particles (self-formed water droplets) are not sufficient for analysis in the region of $x<31 \mathrm{~mm}$, because a potential core should be formed. The order of the maximum velocity is in approximate agreement with that of Bernoulli's theorem $\left(U_{m}\right.$ $=100 \mathrm{~m} / \mathrm{s}$ ). Therefore, in the region downstream of $x=31 \mathrm{~mm}$, the results will be adequate. The axial mean velocity decreases linearly with the relationship of $-0.97 x$ between $x=31$ and $41 \mathrm{~mm}$, after which, the axial mean velocity decreases more rapidly.

The mean velocity profiles across the jet between $x=31$ and $41 \mathrm{~mm}$ are shown in Fig. A-3(b). Each profile is normalized according to $U_{m}$ and the half width $b$. The velocity profiles are almost flat within the jet plane and all the profiles collapse onto a single profile within the extent of the experimental conditions. Therefore, the profiles can be recognized as a self-similar state within the present conditions. The turbulent intensities of the axial
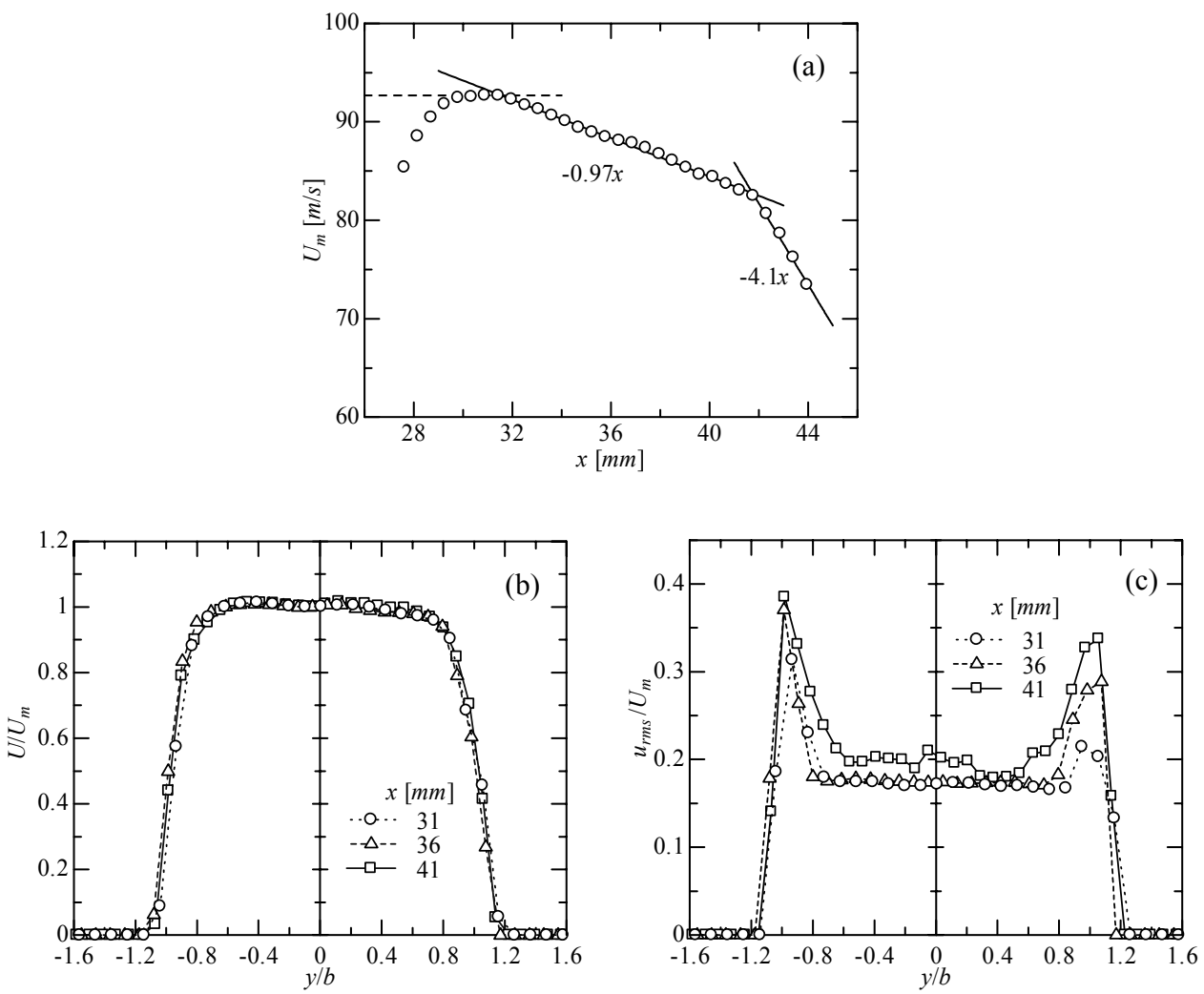

Fig. A-3 (a) Streamwise variation of the axial mean velocity, (b) Mean velocity and (c) turbulent intensity profiles across the jet. 
velocity component are shown in Fig. A-3(c). The profiles show peak values at both edges of the water jet at the water/air boundary. These values are relatively higher than expected, which is probably due to the lack of sufficient numbers of detected water droplets. Therefore, further improvement of the experimental technique is required.

\section{References}

(1) Fukushima, C., Shinhara, Y., Ohtani, K., Nakanishi, S., and Ito, N., Application of Water Jet for Removal of Thermally Sprayed Materials, Surface Modification Technologies XXII, VALAR Docs (2009), pp.329-338.

(2) Ruusuvuori, K., Lahdenpera, K., Oksa, M., Turunen, E., and Lundberg, R., Controlled removal of HVOF hard coatings by abrasive water jet, Thermal Spray 2005 (2005), pp.1016-1020.

(3) Bach, Fr.-W., Bruggemann, P., Louis, H., Schenk, A., and Versemann, R., Dry ice blasting and water jet processes for the removal of thermal sprayed coatings, Thermal Spray 2005 (2005), pp.1542-1548.

(4) Redeker, C.F., Bach, Fr.-W., Copitzky, T., Examination of the dry ice removal process for thermal sprayed coatings by particle image velocimetry, Thermal Spray 2003 (2003), pp.1279-1284.

(5) Ducos, M.D., Richard, F., Matile, O., Warnecke, R., Hume, H., and Debionne, T., New LN2 cryogenic process to strip parts thermal spray coated, Thermal Spray 2008 (2008), pp.695-700.

(6) Scrivani, A., Soranzo, M., Rizzi, G., Bardi, U., and Carafiello, L., On the stripping of turbine blades and vanes: mechanisms and performances of chemical stripping for the removal of NiCrAlY thermal spray coatings, Thermal Spray 2003 (2003), pp.745-748.

(7) Ding, J., Shimizu, S., and Kido, M., Removal of plasma sprayed ceramic coatings by plain water jets, $7^{\text {th }}$ Pacific Rim International Conference on Water Jet Technology (2003), pp.413-420.

(8) Shimizu, S., Kato, H., Ding, J., and Kido, M., Flow structure and Erosive Characteristics of water jet issuing from a fan jet nozzle, Journal of Jet Flow Engineering, ( in Japanese) Vol.21, No.3 (2004), pp.4-10.

(9) Shimizu, S., Structure and erosive characteristics of water jet issuing from fan jet nozzle, $18^{\text {th }}$ International Conference on Water Jetting (2006), pp.337-345.

(10) Xu, J., and Summers, D.A., Experimental evaluation of the performance of fan jet systems, $12^{\text {th }}$ International Symposium on Jet Cutting Technology (1994), pp.37-46.

(11) $\mathrm{Wu}$, S.S., and Kim, T.J., An application study of plain water jet process for coating removal, $8^{\text {th }}$ American Water Jet Conference (1995), pp.779-790.

(12) Chillman, A., Ramulu, M., and Hashish, M., Waterjet peening and surface preparation at $600 \mathrm{MPa}$ : A preliminary experimental study, Journal of Fluids Engineering, Vol.29 (2007), pp.485-490.

(13) Shinhara, Y., Wang, R., Tokuda, T., Kido, M., Harada, Y., and Wada, S., Surface strain measurement of thermally sprayed ceramics coatings under static and cyclic loadings and its application to detection of delamination, Material Transactions, Vol.48, No.7 (2007), pp. 769-774.

(14) Kong, M.C., Axinte, D., and Voice, W., Aspects of material removal mechanism in plain waterjet milling on gamma titanium aluminide, Journal of Material Processing Technology, Vol.210 (2010), pp.573-584.

(15) Mabrouki, T., Raissi, K., and Cornier, A., Numerical simulation and experimental study of the interaction between a pure high-velocity waterjet and targets:contribution to investigate the decoating process, Wear, Vol.239 (2000), pp.260-273.

(16) Momber, A.W., and Kovacevic, R., Fracture of brittle multiphase materials by high energy water jets, Journal of Materials Science, Vol.31(1996), pp.1081-1085. 
(17) Holmes, P., Lumley, J.L., Berkooz. G., and Rowley, C.W., Turbulence, coherent structures, dynamic systems and symmetry, Cambridge University Press, Cambridge (2012), pp.25-27, pp.318-319.

(18) Sawamura, T., Fukunishi, Y., and Kobayashi, R., Velocity measurement of abrasive waterjet by a combination of PIV and PTV, Trans. Jpn. Soc. Mech. Eng. B, (in Japanese ) Vol. 66, No. 641 (2000), pp.50-56. 